\title{
Severe Thrombocytopenia in a Child with Brucellosis
}

A Abu Duya ${ }^{1}$, WYM Alassiry ${ }^{1}$, M Otaif ${ }^{1}$, ME Elawad $^{2}$

\section{INTRODUCTION}

Brucellosis is endemic in Saudi Arabia especially in areas where the local people herd many types of cattle(mainly goats, sheep, camels and cows) Patients acquire the disease by drinking raw milk, eating raw meat or the direct contact with these animals (1-3). It causes a chronic febrile disease with many manifestations.

Hematological abnormalities such as anemia, leucopenia and leukocytosis are commonly encountered in affected individuals (4-6). Rarely pancytopenia and disseminate intravascular coagulation are seen. Isolated Brucella - induced thrombocytopenia has been reported mainly in adult affected patients $(7,8)$. It is extremely rare in children. We present here severe Brucellainduced thrombocytopenia in a child thought to have idiopathic thrombocytopenic purpura (ITP). Once the diagnosis of brucellosis was established and specific treatment (antibiotic combination) was started, the platelets count showed prompt response to this. We advice clinicians in areas where brucellosis is endemic to consider this possibility in children presenting with febrile illnesses and thrombocytopenia.

Keywords: Childhood brucellosis, immunoglobulin, severe thrombocytopenia

Affiliations: ${ }^{1}$ Department of Pediatrics, Asir Central Hospital Abha KSA, ${ }^{2}$ College of Medicine King Khalid University Abha KSA.

Correspondence: Dr ME Elawad, Department of Pediatrics College of Medicine, King Khalid University, Abha PO Box641 KSA. E-mail: mawad76@hotmail.com 


\section{CASE REPORT}

S. A.A. 10 year old boy from Tihama southwestern region of Saudi Arabia was referred from the regional hospital to our unit for further workup. He had 2 weeks history of fever and skin rash. For the last 3 days he became lethargic and felt central abdominal pain. He had intermittent episodes of dark urine and stools. Assessment showed he was febrile $\left(39.3^{0} \mathrm{C}\right) \mathrm{He}$ had purpuric skin rash on legs and papular facial skin rash as well. There was no lymphadenopathy or bone pain. He had no jaundice. Liver was $3 \mathrm{~cm}$ palpable $\mathrm{BCM}$ and spleen could just be tipped. The initial blood count showed severe thrombocytopenia for further workup. Further questioning revealed the family lived in a rural area with close contact with goats and sheep.

Initial workup showed the following results: WBC $\left(5.37 \times 10^{9} / \mathrm{L}\right), \mathrm{HB}(10.9 \mathrm{~g} / \mathrm{dcl})$, Platelets count $\left(7 \times 10^{9} / \mathrm{L}\right)$ and $\operatorname{ESR}(77 \mathrm{~mm} / \mathrm{hr})$. The rest of indices were normal.

Peripheral blood picture showed hypochromia and microcytosis. Lymphocytes looked normal. Platelets were markedly reduced.

Blood film for malaria: negative

Bone marrow aspiration showed: Active marrow (erythropoiesis and leucopoiesis) Megakaryocytes were increased. Lymphocytes showed normal size and morphology.

There were no LD bodies

Patient received a dose of immunoglobulin infusion $(400 \mathrm{mg} / \mathrm{kg}$ stat) as he was thought to have ITP with bleeding.

Peripheral blood smear: Mild anisocytosis, microcytosis, hypochromasia and few polychromatic schistiocytes.

WBC: normal

Lymphocytes: normal 
Platelets: markedly reduced.

Blood film for malaria negative

Bone marrow Aspiration

Active normocellular.

Erythropoiesis: active normoblastic maturation with mild signs of dyserthropoisis

Leucopoiesis: normal maturation. + Prominent granulation. With mild eosinophilia.

Megakaryocytes increased mature productive-. Immature forms are seen.

Lymphocytes normal range and morphology

No LD bodies seen.

Few reactive histiocytes

Patient management: received one dose of immunoglobulin infusion $400 \mathrm{mg} / \mathrm{kg}$ stat as he was thought to have ITP with bleeding. Once the result of brucella serology was obtained (Brucella abortus titer $>1280$, \&melitensis $>1280$ ), he was started on: Gentamicin, Rifampicin and co trimoxazole (Bactrim) Fever subsided within 3 days. There was prompt increase in platelet count from $27 \times 10^{9} / \mathrm{L}$ to $109 \times 10^{9} / \mathrm{L}$ in 48 hours.

Two weeks later patient platelets count rose to $120 \times 10^{9} / \mathrm{L}$ and two months later platelets count was normal $\left(300 \times 10^{9} / \mathrm{L}\right)$

\section{DISCUSSION}

This case represents the rare association of severe symptomatic isolated thrombocytopenia in a child with acute brucella infection mimicking immune thrombocytopenia. It resulted in both gastrointestinal and renal bleeding with significant echymotic skin eruption. 
It is important to obtain through history in cases of Immune thrombocytopenia in areas where infectious causes like brucella are endemic. It is also vital to test for brucellosis once a patient had a non-explained febrile illness. The normal result of active bone marrow clearly points to the fact that the reduction is due to peripheral destruction. This is thought to be due to multiple factors: endotoxin generation by the organism leads to destruction of platelets and other cells manifesting as pancytopenia (8). It is also possible that a platelet specific antigen can lead to isolated thrombocytopenia (8-12). Other contributory factors like hyperslenism and disseminated intravascular coagulation are also encountered here (9-12).

It is interesting to note the prompt response to antibiotic therapy although it is possible that the immunoglobulin dose he received has helped in this. This is interesting because it points out to the possible role of immunoglobulin therapy in cases of severe thrombocytopenia complicating brucella infection. There are few reports of using this therapy mainly with steroids. It is will be interesting if further trials are carried out to explore the potential usefulness of immunoglobulin therapy alone in cases of brucella induced thrombocytopenia.

\section{CONCLUSION}

Severe thrombocytopenia is rare in childhood brucellosis. Prompt early antibiotic therapy restores the platelets deficiency. There is potential benefit of immunoglobulin infusion with or without corticosteroid therapy especially in serious cases complicated with overt clinical bleeding. 


\section{REFRENCES}

1. Bilal NE. Jamjoom GA, Bobo RA, Aly OFM, El-Nashar NM. Brucellosis in the Asir region of Saudi Arabia. Saudi Med J.1991; 12:37-41.

2. Al-Eissa YA. Brucellosis in Saudi Arabia: Past, present and future. Ann Saudi Med. 1999 ;19(5):403-5

3. Al-Eissa Y, al-Nasser M. Hematological manifestations of childhood brucellosis. Infection. 1993; 21:23-26.

4. _Al-Eissa Y, Assuhaimi S, Al-Fawaz I, Higgy K, Al-Nasser M, AlMobaireek K. Pancytopenia in children with brucellosis: Clinical manifestations and bone marrow findings. Acta Haematol.1993; 89(3) 132-6

5. Crosby E, Llosa L, Miro Quesada M, Carrillo C, Gotuzzo E. Hematologic changes in brucellosis. J Infect Dis. 1984 Sep; 150(3):419-424

6. El-Koumi MA, Afify M and H Al-Zahrani S. A Prospective Study of Brucellosis in Children: Relative Frequency of Pancytopenia. The Mediterranean Journal of Hematology and Infectious Diseases 2013; doi 10.4084MJHID2013.011

7. Suleyman B ,Serdar S, Tahsin S A, et al. An Atypical Presentation of Brucellosis in a Patient with Isolated Thrombocytopenia Complicated with Upper Gastrointestinal Tract Bleeding Case Reports in Medicine Volume 2012 (2012) doi 10.1155/2012/473784

8. Pappas G., Kitsanou M, Christou L, and Tsianos E Pancytopenia Attributed to Brucellosis and Other Mechanisms of Brucella-InducedThrombocytopenia. Am. J.Hematol; 2004. 75:139-141 
9. Yilmaz M, Tiryaki O, Namiduru M, Okan V, Oguz A,Buyukhatipoglu H, et al. Brucellosis-induced immune thrombocytopenia mimicking ITP: a report of seven cases. Int JLab Hematol 2007; 29(6): 442-445.

10. B Benjamin. Acute thrombocytopenic purpura in childhood brucellosis Annals of Tropical Paediatrics International Child Health; 1995; 15(3):189-92

11. Atluri VL, Xavier MN, de Jong MF, den Hartigh AB, Tsolis RM.Interactions of the human pathogenic Brucella species with their hosts. Annu Rev Microbiol 2011; 65: 523541.

12. Pappas G, Kitsanou M, Christou L, Tsianos E. Immune thrombocytopenia attributed to brucellosis and other mechanisms of 2004;75(3) 139-41 